\title{
DEVELOPMENT OF ECOLOGICALLY SAFE TECHNOLOGY OF WASTE MYCELIA RECYCLING
}

\author{
Oksana Yegorova \\ Department of General Ecology, Pedagogy and Psychology \\ Cherkasy State Technological University \\ 460 Shevchenko str., Cherkasy, Ukraine, 18006 \\ yegorova.ok@gmail.com
}

\begin{abstract}
Chitosan is a cationic polymer derived by deacetylation of chitin obtained from crustaceans. Biodegradable and mucoadhesion properties of chitosan have recently led to increasing the interest. Chitosan can be used as raw material for the manufacture of films, membranes and fibers, in such branches as medicine, agriculture, veterinary medicine, biotechnology, cosmetics and pulp, and paper industry. Previously it was investigated that in Aspergillus Niger cell wall constituents, chitin comprises of $42 \%$ and also researchers confirmed that the chitosan content of fungi depends on fungal strains, mycelial age, cultivation medium and conditions [1]. In the paper the results of the study of physical and chemical properties of obtained samples of chitosan are shown. The influence of initial parameters of the process on the quality of chitosan is investigated. Use of the biomass to produce chitosan on the basis of the developed methodology is shown. It is found that the resulting chitosan is characterized by low values of ash content, moisture content and the value is within 75-82\%. A further development of the scientific basis for the creation of an efficient, competitive and environmentally safe technologies for utilization mycelial biomass of the fungus Aspergillus Niger with the production of a valuable product is chitosan, which is in contrast to the known allows to reduce production costs by $10-80 \%$ (by using not concentrated solutions of chemicals and low temperature process. This leads to reducing the cost of reagents and electricity. The calculation was performed on indicators such as net present value, internal rate of return and payback period.) The use of the developed technological schemes in practice allows utilization of mycelial waste with the aim of obtaining from them valuable product of chitosan, and to ensure the improvement of ecological situation in the region.
\end{abstract}

Keywords: chitosan, filamentous waste, processing technology, recycling, Aspergillus Niger.

\section{Introduction}

Environmental studies that were conducted in the last decades in many countries and in Ukraine showed that the increasing devastating impact of anthropogenic factors on the environment leads to the brink of crisis [2-4] Among the various components of the environmental crisis (depletion of raw material resources, lack of clean fresh water, possible climate catastrophe) is the most threatening, took the problem of pollution of irreplaceable natural resources - air, water and soil waste management industry. Waste water is generated in the production process, which differs in their physical properties, chemical composition and degree of contamination, and environmentally hazardous wastes that are stored in the fields of filtration and adversely affect the ecological safety of the regions.

Academic interest to chitin, chitosan and chitin-containing compounds increased last years. Chitosan is mainly obtained by deacetylation of chitin (poly- $\beta-(1,4)$ acetylglucosamine) obtained from wastes of the sea-food industry (crab and shrimp shells and squid pens) and presents all the advantages of a low-cost renewable raw material. Chitosan is an effective sorbent for metal species. Chitosan can be used as raw material for the manufacture of films, membranes and fibers in such fields as medicine, agriculture, veterinary medicine, biotechnology, cosmetics and pulp and paper industry [5-8]. According to the analysis of literary sources revealed that one of the cheapest sources of chitin can be the mycelium of mold fungus Aspergillus Niger. Currently existing methods of removal of chitin and chitosan from waste mycelia of the fungus Aspergillus Niger based on the use of concentrated solutions of acids and alkalis (30-50\%) and a large amount of solvents [9-13]. In this regard, the actual problem is a modification of known methods for the isolation of mycelial chitosan from waste using available and inexpensive reagents. 


\section{Materials and Methods}

The first appropriate step was to conduct physical and chemical studies of the mycelial biomass of fungus Aspergillus Niger - waste biotechnological production of citric acid. For experimental studies with the purpose of properties comparison, samples of biomass were taken from different fermentors after a complete cycle of fermentation. The cultivation of biomass was carried out by submerged fermentation on beet molasses under virtually the same conditions. Obtained experimental data are given in Table 1, further confirmed the already known fact that the chemical composition of biomass and its characteristics are significantly influenced by the conditions of fermentation of the fungus Aspergillus Niger.

Table 1

Characteristics of mycelial waste of the fungus Aspergillus Niger

\begin{tabular}{|c|c|c|c|c|c|c|c|}
\hline \multirow{2}{*}{ Sample of biomass" } & \multirow{2}{*}{ Ash content, \% } & \multirow{2}{*}{ Humidity, \% } & \multicolumn{4}{|c|}{ Content, \% } & \multirow{2}{*}{ pH } \\
\hline & & & Fats & Proteins & $\mathrm{ChCS}^{* *}$ & $\mathbf{A O M}^{* * *}$ & \\
\hline 1 & 10,5 & 70 & 1,65 & 18,5 & 22,5 & 58,4 & 3,6 \\
\hline 2 & 10,0 & 70 & 1,64 & 18,2 & 23,0 & 58,2 & 3,6 \\
\hline 3 & 9,0 & 74 & 1,62 & 18,7 & 22,0 & 57,7 & 3,4 \\
\hline 4 & 8,2 & 72 & 2,34 & 14,6 & 19,5 & 61,6 & 3,7 \\
\hline 5 & 8,6 & 72 & 2,35 & 14,4 & 20,8 & 62,5 & 3,6 \\
\hline 6 & 8,0 & 75 & 2,30 & 15,0 & 20,0 & 62,7 & 3,6 \\
\hline
\end{tabular}

Note: ${ }^{*}$ - samples of biomass were selected from different fermentors; ${ }^{* *}$ - chitin-containing complexes; ${ }^{* * *}-$ accompanying organic matter

It is established that the biomass, which were obtained in strict compliance with technology of deep fermentation of the fungus Aspergillus Niger on beet molasses (biomass № 4-6), in its composition contain about $20 \%$ of chitin in the form chitin-containing complexes. For biomass, selected from fermentor, a breach of the conditions of the technological regime, that is, when there is insufficient aeration, low temperature, poor quality of the underlying molasses (samples № 1-3 respectively), characterized by the increase in the number of chitin to $22 \%$.

The increase of the amount of chitin complexes in biomass can be regarded as a response of the fungus to adverse environmental conditions and protects cells from their actions with these sustainable complex biopolymers. A consequence of the low quality of the source beet molasses, which is the presence in its composition of a significant amount of mineral salts, there are higher values of ash content of the mycelial waste. Partial extraction of soluble salts from the biomass and reduce of its ash content contributes to pre-washed thoroughly with water (biomass № 4, 6). An important task that was set when the method of producing chitosan, was the choice of optimal conditions of processing mycelial waste with the aim of obtaining a product with a stable chemical composition regardless of the quality of waste mycelia of the fungus Aspergillus Niger.

Method for isolation of chitosan from waste Aspergillus Niger consists of the following steps:

1. Diacetylguanine chitosan $37 \%$ solution of $\mathrm{NaOH}$ at $\mathrm{t}=110^{\circ} \mathrm{C}$ for 7 hours.

2. Cooling the mix and a thorough rinsing with distilled water to $\mathrm{pH}=12,5$, filtering the mixture.

3. Extraction of chitosan from the precipitate by acetate acid.

4. The deposition of chitosan solution of $\mathrm{NaOH}$, rinsing the precipitate with distilled water followed by filtration and drying the precipitate. 
During the study of physicochemical characteristics of chitosan it is determined (test setup of the physical and chemical characteristics was determined empirically):

1. The product yield according to the formula:

$$
\mathrm{W}=\frac{\mathrm{m}}{\mathrm{m}_{\mathrm{o}}} \cdot 100 \%
$$

where $\mathrm{m}$ - the weight of chitosan, $\mathrm{g} ; \mathrm{m}_{0}$ - the weight of the portion of the original biomass, $\mathrm{g}$.

2. Ash content - combustion of the sample of chitosan for 2 hours at $t=800{ }^{\circ} \mathrm{C}$.

3 . The moisture content of chitosan was determined according to the difference of the masses of the original sample $(1 \mathrm{~g})$ and dried for one hour at $\mathrm{t}=110^{\circ} \mathrm{C}$.

4. The calculations were carried out according to the formula:

$$
\mathrm{W}_{\mathrm{H}_{2} \mathrm{O}}=\frac{\mathrm{g}_{1}-\mathrm{g}_{2}}{\mathrm{~g}_{1}} \cdot 100 \% \text {, }
$$

where $\mathrm{g}_{1}, \mathrm{~g}_{2}$ - the mass of wet and dried chitosan, accordingly, $\mathrm{g}$.

5 . The $\mathrm{pH}$ of the aqueous extract was determined after three minute boil chitosan sample weighing $5 \mathrm{~g}$ in 50 of distilled water followed by filtration of the suspension through a paper filter and cooled. The $\mathrm{pH}$ measurements were carried out on a universal odometer «Ecotest-2000» (Russia).

6 . The degree of swelling were determined by soaking $4 \mathrm{~g}$ of chitosan in distilled water during the day with fixing the initial and final volumes. The calculation was performed according to the formula:

$$
\mathrm{S}_{\mathrm{n}}=\frac{\mathrm{V}_{\mathrm{n}}-\mathrm{V}_{\mathrm{o}}}{\mathrm{m}}
$$

where $\mathrm{S}_{\mathrm{n}}$ - the degree of swelling, $\mathrm{ml} / \mathrm{g} ; \mathrm{V}_{0}$ та $\mathrm{V}_{\mathrm{n}}$ - volumes of dry and swollen sample, accordingly, $\mathrm{cm}^{3}$; $\mathrm{m}-$ the dry weight of the sample, $\mathrm{g}$.

7. Water holding capacity was determined by soaking the sample chitosan weight of $2 \mathrm{~g}$ in distilled water for 20 hours, followed by filtration and centrifugation for 10 minute at a speed of $4000 \mathrm{rpm}$. The chitosan was dried to constant weight at $105^{\circ} \mathrm{C}$. The calculation was performed according to the formula:

$$
\mathrm{WHC}=\frac{\left(\mathrm{m}_{1}-\mathrm{m}_{0}\right)}{\mathrm{m}_{1}} \cdot 100 \%,
$$

where WHC - water holding capacity, $\% ; \mathrm{m}_{1}$ and $\mathrm{m}_{0}$ - the mass of the sample before and after drying.

8. Diacetylguanine degree (DD), which characterizes the degree of conversion of chitin to chitosan, was determined by several methods: photocolorimetric, potentiometric and IR spectroscopy.

The photocolorimetric method is based on the interaction of chitosan amino groups with a pigment ninhydrin. To construct the calibration curve, solutions of result standardized chitosan with $\mathrm{DD}=40 \%$ acetic acid were prepared with the addition of a phosphate buffer mixture and ninhydrin. The optical density was measured on photocolorimeter KFK-2 MP (Russia) at a wavelength of $400 \mathrm{~nm}$. Degree diacetylguanine calculated by the formula:

$$
\mathrm{DD}=\frac{\mathrm{m}_{\mathrm{x}}}{\mathrm{m} \cdot 10^{3}} \cdot 100 \%
$$

Potentiometric method consists on the construction of titration curves. Titration curves were obtained by titration with alkali solution of chitosan with chloride acid. Weighed $0,2 \mathrm{~g}$ of chitosan was dissolved under stirring on a magnetic stirrer (MM-5, Russia) for 1 hour. The resulting solution 
was titrated with $0,03 \mathrm{~N}$ solution of sodium hydroxide to a $\mathrm{pH}$ of about 11 . On the calibration chart, the first leap on the titration curve corresponds to an excess of hydrochloric acid, and the second concentration of amino groups in chitosan Nawaz.

For spectral studies, the samples of chitosan were tableted by compacting highly dispersed sample with $\mathrm{KBr}$ with a ratio of $1 \mathrm{mg}: 70 \mathrm{mg}$. Tablets are pressed under the pressure of $10 \mathrm{MPa}$. Preparation of thus samples gave the opportunity to obtain spectra in the region 4000-400 $\mathrm{cm}^{-1}$. IR spectra were recorded by using a Fourier spectrometer Perkin Elmer Spectrum One (USA).

\section{The results and analysis of waste mycelia and chitosan}

An important task that was set when the method of producing chitosan, was the choice of optimal conditions of processing mycelial waste with the aim of obtaining a product with a stable chemical composition regardless of the quality of waste mycelia of the fungus Aspergillus Niger.

Samples of chitosan were obtained by changing conditions of the technological process

(Table 2). In Table 3 presents the physico-chemical characteristics of produced chitosan.

Table 2

The conditions of the production process

\begin{tabular}{|c|c|c|c|c|c|}
\hline № & $\mathrm{W}(\mathrm{NaOH}), \%$ & Temperature, ${ }^{\circ} \mathrm{C}$ & $\begin{array}{l}\text { The duration of } \\
\text { the process, hours }\end{array}$ & $\begin{array}{l}\text { The amount } \\
\text { extractions of chitosan }\end{array}$ & $\begin{array}{l}\text { The duration of } \\
\text { each extraction, min }\end{array}$ \\
\hline 1 & 37 & 110 & 7 & 3 & 30 \\
\hline 2 & 37 & 110 & 3 & 3 & 30 \\
\hline 3 & 40 & 110 & 7 & 3 & 10 \\
\hline 4 & 45 & 110 & 7 & 1 & 100 \\
\hline 5 & 37 & 110 & 7 & 1 & 80 \\
\hline 6 & 45 & 110 & 7 & 1 & 80 \\
\hline 7 & 42 & 120 & 7 & 1,5 & 100 \\
\hline 8 & 40 & 110 & 7 & 1 & 100 \\
\hline
\end{tabular}

Table 3

Physico-chemical characteristics of obtained chitosan

\begin{tabular}{|c|c|c|c|c|c|c|c|}
\hline № & Ash content, $\%$ & $\begin{array}{l}\text { The moisture } \\
\text { content, } \%\end{array}$ & pH & $\begin{array}{l}\text { The degree of } \\
\text { swelling, } \mathrm{ml} / \mathrm{g}\end{array}$ & WHC, \% & The product yield, $\%$ & DD, \% \\
\hline 1 & 2,585 & 75 & 5,2 & 0,68 & 76 & 3,00 & 23,0 \\
\hline 2 & 2,585 & 80 & 5,2 & 0,60 & 80 & 4,97 & 67,4 \\
\hline 3 & 2,585 & 82 & 5,2 & 0,54 & 82 & 26,25 & 51,3 \\
\hline 4 & 2,585 & 88 & 5,2 & 0,48 & 86 & 12,50 & 71,6 \\
\hline 5 & 2,585 & 75 & 5,2 & 0,676 & 72 & 4,35 & 82,0 \\
\hline 6 & 2,585 & 75 & 5,2 & 0,60 & 70 & 3,45 & 75,0 \\
\hline 7 & 2,585 & 80 & 5,2 & 0,61 & 82 & 3,00 & 78,6 \\
\hline 8 & 2,585 & 82 & 5,2 & 0,546 & 85 & 5,80 & 69,6 \\
\hline
\end{tabular}

Analysis of the data given in Table 2, 3 showed that all the samples of chitosan are characterized by a low value of ash content and humidity value is in the range of $75-82 \%$. The yield of chitosan is not stable, and in our opinion, its value is affected by the process temperature and the concentration of $\mathrm{NaOH}$ used for reaction diacetylguanine. DD of chitosan ranges from $23 \%$ to 
$80 \%$. In our opinion, the most favorable condition for obtaining chitosan in the production process is number 5 (Table 2), which allows to obtain chitosan with high value of degree diacetylguanine $82 \%$ (Table 3).

An important parameter for chitosan, which determines its physico-chemical properties, is $\mathrm{DD}$, which reflects the degree of substitution of acetyl groups on the amino group in the molecule aminopolysaccharide. Classical methods for determining the DD of chitosan in the solution is photometry and conductometry - conductometric direct titration of acids, however, for chitosan, in most cases, using back titration with alkali, as the direct titration of chitosan is longer. The content of chitosan by the photometric method was determined by calibration line, and the corresponding formula calculates the degree diacetylguanine for the studied samples (Fig. 1).

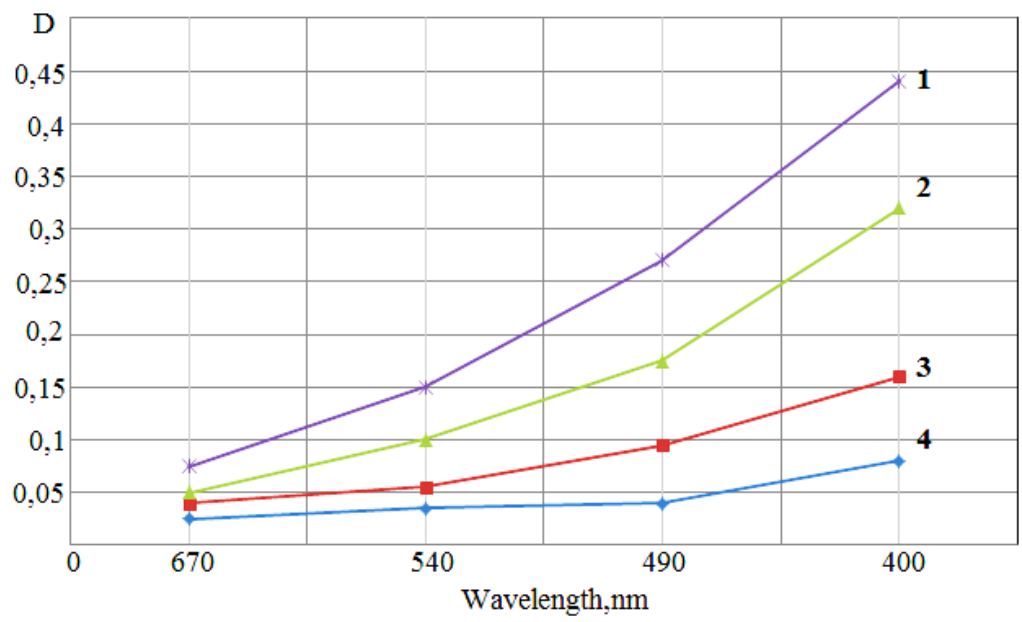

Fig. 1. Absorption spectrum of chitosan solutions. The mass of chitosan in the solution: 1 - $20 \mathrm{mg} ; 2$ - $15 \mathrm{mg} ; 3$ - $10 \mathrm{mg} ; 4-5 \mathrm{mg}$

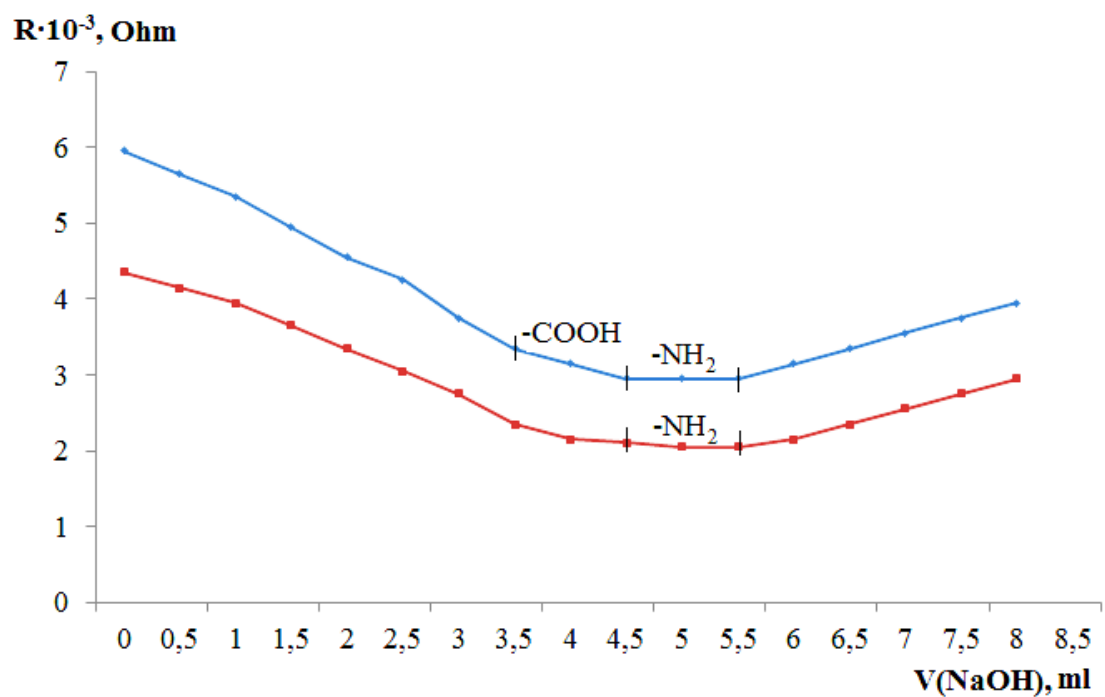

Fig. 2. The curves of conductometric titration of chitin-containing complexes (1) and chitosan (2)

When conductometric titration according to the obtained data, the curves of conductometric titration were built (Fig. 2). The calculations were carried out according to prescribed formulas. The results of the calculations are given in Table 4.

The degree of conversion of chitin to chitosan in the cell wall of the fungus Aspergillus Niger (sample № 5) was measured by method of IR-spectroscopy.

As can be seen from Fig. 3, the spectrum of the chitosan sample obtained in accordance with the flowcharts (if use the solution of $\mathrm{NaOH}$ for processing mycelial waste) in the region $1500-1700 \mathrm{~cm}^{-1}$ 
manifested intense absorption bands characteristic of chitin with highs $1540 \mathrm{~cm}^{-1}$ (amide II), 1640 and $1620 \mathrm{~cm}^{-1}$ (amide I). The group of absorption bands of medium intensity in the region 1000-1200 $\mathrm{cm}^{-1}$ can be assigned to vibrations of $\mathrm{C}-\mathrm{O}$ bonds in ether groups. An intense absorption band at $1320 \mathrm{~cm}^{-1}$ corresponds to the vibration of $\mathrm{C}-\mathrm{H}$ groups. The broad absorption band from 2800 to $3600 \mathrm{~cm}^{-1}$ with a maximum of $3450 \mathrm{~cm}^{-1}$ indicates the presence of a valence $\mathrm{O}-\mathrm{H}$ vibration, excited by hydrogen bonds.

Table 4

The results determine the degree of diacetylguanine (DD) solution of chitosan photometric and conductometric methods

\begin{tabular}{ccc}
\hline Samples of chitosan & DD, \% & conductometric methods \\
\hline 1 & 24,0 & 25,2 \\
2 & 67,5 & 67,3 \\
3 & 51,9 & 52,5 \\
4 & 72,0 & 73,2 \\
$\mathbf{5}$ & $\mathbf{8 2 , 0}$ & $\mathbf{8 1 , 8}$ \\
6 & 75,4 & 76,6 \\
7 & 77,8 & 79,0 \\
8 & 70,1 & 70,5
\end{tabular}

According to the literature data, absorption bands in the region $2800-3100 \mathrm{~cm}^{-1}$ with maxima 2830 and $2920 \mathrm{~cm}^{-1}$ characterize the stretching symmetric and asymmetric vibrations of $\mathrm{C}$-H groups, and a maximum of $3050 \mathrm{~cm}^{-1}$ corresponds to the vibration of N-H. In the region $500-900 \mathrm{~cm}^{-1} \mathrm{observed}^{-}$ group of bands that can reliably be attributed to the skeletal vibrations of polysaccharide cycles [14].

When comparing the properties of the obtained samples of chitosan obtained according to the proposed method, it was found that in the IR spectra of all samples of differences practically is not observed. The main difference in the spectra is the decrease in the intensity and halfwidth of the band of C-H stretching vibrations in the region of $2920 \mathrm{~cm}^{-1}$ with increasing concentration of alkaline solutions.

Such change, in our opinion, is due to the increase of order and decrease of branching of the polysaccharide molecules. The increase in branching of the molecules leads to the additional formation of hydrogen bonds with an energy that causes additional spreading of the strip. It might increase and the intensity of the band due to Fermi resonance, which is characteristic for oxygen-containing molecules.

Thus, the analysis of the IR spectra of chitosan further confirmed that when the concentration of the alkaline solutions, which are used for processing mycelial waste, there is a tendency to increase of ordering in the structure that might disrupt its fibrous structure and have a negative impact on sorption properties.

As can be seen from Fig. 3, the intensity of characteristic bands 1640 and $1620 \mathrm{~cm}^{-1}$ increases, which is a proof of the high degree deacetylase complexes. We also made sure that the formation of chitosan into the structure of the complexes when the reaction is carried out, diacetylguanine is characterized by spectral changes in the region $1500-1700 \mathrm{~cm}^{-1}$.

Technological scheme of chitosan production from waste mycelia (Fig. 4) was proposed on the basis of the methods of disposal of the waste. A preformed solution of sodium hydroxide with the reagent plant supplied to the mixer 1, which is also in the pipeline, is mycelia biomass. This mixer is heated with saturated steam to a temperature of $115^{\circ} \mathrm{C}$. Concentration of the mixture in the apparatus should be $40 \%$. The mixing process is carried out for 7 hours. Thereafter, the resulting slurry is fed to a drum vacuum filter 2 , where the separation of the alkaline solution and the 
precipitate. The pressure in the apparatus is about $0,085 \mathrm{MPa}$. After filtering the alkaline solution is given for recycling, and obtained sludge is supplied to the mixer 3, where a solution of acetic acid is supplied over pipeline from reagent production unit. Here is extraction of chitosan from the resulting precipitate within a specified time, after which the mixture is fed to the drum vacuum filter 4 , where the separation of the precipitate from the filtrate. The resulting precipitate going to disposal and the filtrate is supplied to the mixer 5 , where in the pipeline is a sodium hydroxide solution to precipitate the chitosan. After deposition of chitosan, the suspension flows into the sump 6 . Clarified water is recycled, and the resulting precipitate was fed to the centrifuge 7 dewatering, after which it is sent to the mixer 8 where it is washed with distilled water to $\mathrm{pH}$ close to neutral. Then re-centrifugations had done in the apparatus 9. Drying of the precipitate (chitosan) occurs in a drum dryer 10, and the resulting chitosan enters the container.

The cost of the project will depend on production capacity (tones/year), the selected technological scheme, technological equipment, buildings, communications, etc.

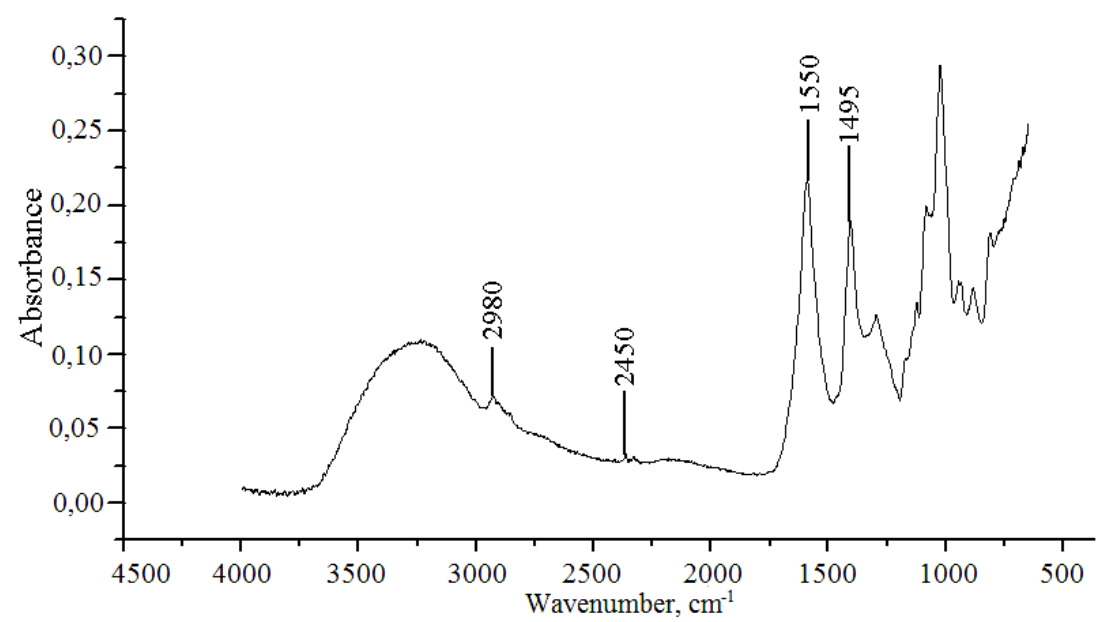

Fig. 3. IR spectra of chitosan obtained by the extraction method (V example)

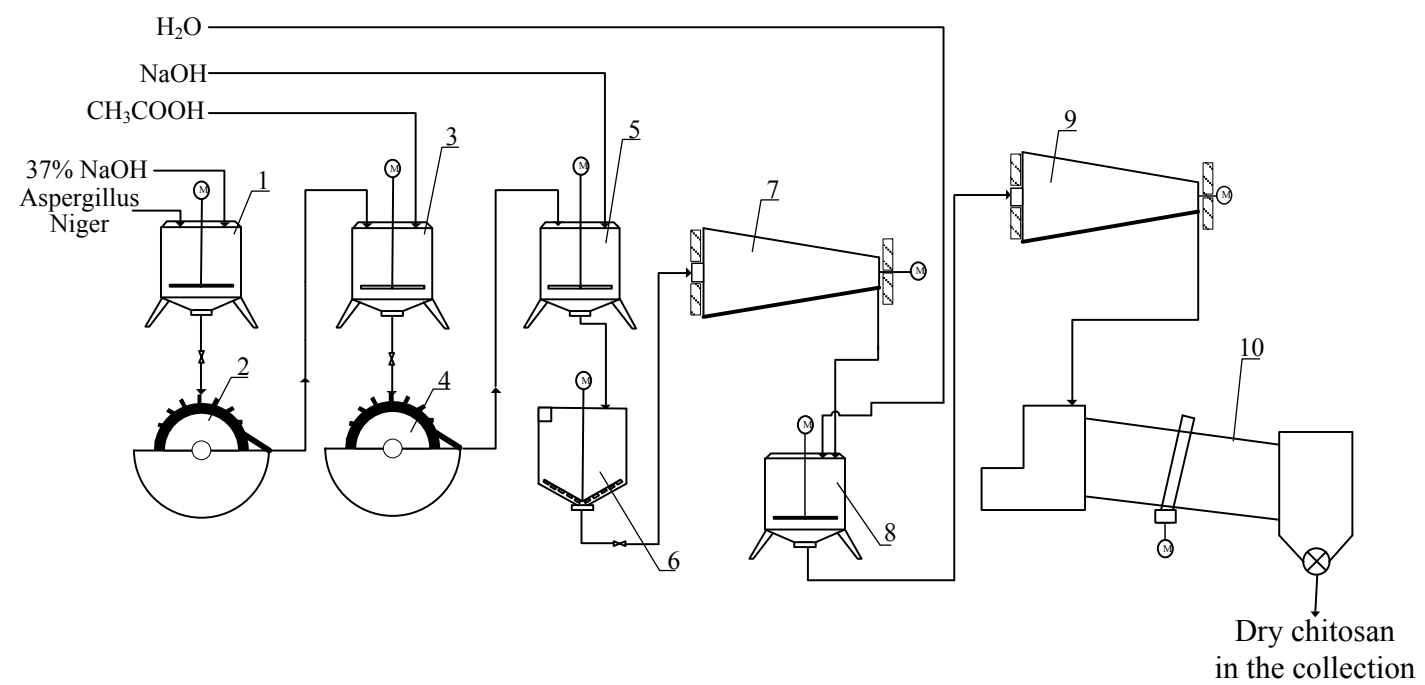

Fig. 4. Technological scheme of production of chitosan from mycelial biomass: 1 - contact apparatus; 2, 4-drum vacuum filter; 3, 5, 8- mixer; 6-sump; 7, 9 -centrifuge; 10 -drum dryer

\section{Conclusions}

The possibility of recycling and secondary use of large mycelial biomass of the fungus Aspergillus Niger in various consumer goods to minimize its negative impact on the environment is theoretically substantiated and experimentally proved. 
Using technology developed by the scheme in practice will recycling mycelial biomass of the fungus Aspergillus Niger, industrial reduce pressure on the environment, ensure improvement of ecological situation in the region and will provide a valuable product - chitosan.

The resulting secondary raw materials - chitosan - can be used for the production of films, membranes and fibers in areas such as medicine, agriculture, veterinary science, biotechnology, food, perfumes and cosmetics, pulp and paper industry.

Energy-saving process of obtaining valuable aminopolysaccharide-chitosan from biomass of fungus is developed Aspergillus Niger - waste of production of citric acid including the process of chemical treatment with alkali solution followed by heat treatment and extraction. The technological scheme of obtaining chitosan from mycelial biomass was created. Analysis of experimental samples showed that the quality is not inferior to chitosan obtained according to the classical scheme, but for DD, even surpasses them.

Studied impact of processes of alkaline processing of mycelial waste on the morphological structure of chitosan is shown that use of alkaline solutions with a high concentration of the product is characterized by a low value of the purity of the product.

It is planned to continue research towards chitosan and zeolite-based sorbents for sewage treatment from ions of heavy metals.

\section{References}

[1] Pochanavanich, P., Suntornsuk, W. (2002). Fungal chitosan production and its characterization. Letters in Applied Microbiology, 35 (1), 17-21. doi: 10.1046/j.1472-765x.2002.01118.x

[2] Hutsuliak, H. D. (2004). Ekoloho-ekonomichni problemy v Ukraini i napriamy yikh vyrishennia. Naukovyi visnyk NLTU Ukrainy, 14.3, 207-214.

[3] Zbirnyk naukovykh statei II-i vseukrainskyi zizd ekolohiv z mizhnarodnoiu uchastiu (2009). Vinnytsia: FOP Danyljuk, 603.

[4] Monin, A. S., Shishkov, N. A. (1991). Globalnye ekologicheskie problemy. Nauki o Zemle. Znanie, 136.

[5] Krasavtsev, V. E. (1999). Krill as promising raw material for the production of chitin in Europe. International conference of the Chitin Society, 1-3.

[6] Kennedy, J., Paterson, M. (1994). Chitin Enzymology. Carbohydrate Polymers, 25 (1), 61-61. doi: 10.1016/0144-8617(94)90165-1

[7] Rane, K. D., Hoover, D. G. (1993). Production of Chitosan by fungi. Food Biotechnology, 7 (1), 11-33. doi: 10.1080/08905439309549843

[8] White, S. A., Farina, P. R., Fulton, I. (1979). Production and isolation of chitosan from Mucor rouxii. Appl Environ Microbiol, 38 (2), 323-328.

[9] Nudga, L., Ganicheva, S., Petrova, V., Bystrova, E., Lvova, E., Galkin, A., Petropavlovsky, G. (1997). Sorption of ions of Cr(III) chitin-glycanova complex isolated from mycelium of the fungus Aspergillus Niger, cultured in different conditions. Journal of applied chemistry, 70 (2), 242-246.

[10] Kogan, G., Machova1, E., Chorvatovicova, D., Slovakova, L. (1997). Chitin-glucan complex of Aspergillus Niger and its derivatives: antimutagenic and antiinfective activity. Proc. of the third Asia-Pacific chitin and chitosan Symposium, Taiwan, 372-379.

[11] Starostina, I. V., Ovcharova, I. V. (2012). Obtaining foam slurry of waste containing protein in a high-frequency electromagnetic field. Modern problems of science and education, 6. Available at: https:// www.science-education.ru/pdf/2012/6/647.pdf

[12] Kapoor, A., Viraraghavan, T. (1998). Application of immobilizedaspergillus niger, biomass in the removal of heavy metals from an industrial wastewater. Journal of Environmental Science and Health, Part A, 33 (7), 1507-1514. doi: 10.1080/10934529809376801

[13] Zhao, Z. P., Wang, Z., Wang, S. C. (2003). Formation, charged characteristic and BSA adsorption behavior of carboxymethyl chitosan/PES composite MF membrane. Journal of Membrane Science, 217 (1-2), 151-158. doi: 10.1016/s0376-7388(03)00105-4

[14] Tereshina, V., Memorskaya, A., Feofilova, E., Nemtsev, D., Kozlov, V. (1997). Isolation of polysaccharide complexes from mycelial fungi and determination of their deacetylation degree. Microbiology, 66 (1), 70-75. 